\title{
Tipografia 'desconstrucionista' e o modelo triádico de Peirce
}

\author{
'Deconstructionist' typography and Peirce's triadic model
}

\begin{abstract}
Derrida, Desconstrução, Peirce, Pós-estruturalismo, Tipografia
A teoria literária pós-estruturalista de Jacques Derrida influenciou toda uma geração de designers gráficos na década de (19)80, inicialmente na Califórnia, Estados Unidos, promovendo uma alternativa a tendência em voga até aquele momento: o Estilo Internacional. Desta confluência de idéias surge um novo conceito no âmbito do design gráfico: a tipografia 'desconstrucionista'. Entretanto, sob um olhar semiótico, a tipografia configura-se em um sistema de signos que extrapola a esfera lingüística. Neste artigo, a tipografia 'desconstrucionista' é analisada à luz do modelo semiótico proposto por Charles Sanders Peirce.
\end{abstract}

\section{Derrida, Deconstruction, Peirce, Post-structuralism, Typography}

The post-structuralist literary theory by Jacques Derrida influenced a whole generation of graphic designers in the (19)80s, starting in Califórnia, USA, and offering an alternative to the mainstream course: the International Style. From this gathering of ideas breaks out a new concept in the field of graphic design: 'deconstructionist' typography. Under a semiotic perspective however, typography configures a system of signs that outbreak the linguistic territory. This article presents 'deconstructionist' typography analysed under the light of the semiotic model proposed by Charles Sanders Peirce.

\section{Tipografia 'desconstrucionista'}

Este texto surgiu da necessidade de definir o objeto de estudo de uma pesquisa em andamento, cujo título inicialmente proposto foi: "Tipografia pós-moderna no Brasil: o produto da estética 'des-construcionista' e suas representações". Trata-se de um recorte muito específico de um tema mais amplo, o design gráfico no final do século XX, e que requer uma investigação e delimitação preci-sas já que apropria-se de um termo oriundo dos campos da filosofia, lingüística, semiótica e antro-pologia: 'desconstrução'. As investigações iniciais, na época de elaboração da proposta da men-cionada pesquisa, estiveram circunscritas a publicações no âmbito do design gráfico, e levaram à compreensão de que o termo 'desconstrução', quando aplicado ao design gráfico, indicava uma tendência estética ou um estilo gráfico. No entanto, ao iniciar a fase de definição do objeto de es-tudo, no início de 2006, foi possível aprofundar a origem exata do termo e, mais ainda, perceber que 'desconstrução' diz respeito a um determinado questionamento conceitual que veio, eventu-almente, a definir produtos que ficaram estigmatizados por possuírem determinado estilo visual. Um outro fator de interesse, nesta fase da investigação, seria identificar uma linha semiótica que oferecesse um instrumental adequado para a análise do objeto de pesquisa definido: a tipografia 'desconstrucionista' no Brasil.

A corrente investigação remete a um passado não muito distante, os anos (19)70, que viram despontar pouco a pouco alternativas ao Estilo Internacional - ou Suíço - no trabalho de Odermatt \& Tissi em Zurique, Wolfgang Weingart na Basiléia - ambos na Suíça, entre outros. Weingart, em entrevista concedida a Priscila Farias em 1995, assim explica qual foi sua motivação:

\footnotetext{
' Fazer algo completamente diferente do que as pessoas estavam fazendo naquele momento. Naquele pe-ríodo, o Estilo Internacional reinava na Suíça e em todo o mundo. Eu sentia uma necessidade de mudar, mas não tinha regras específicas para isso. (...) Os tipógrafos da época nunca colocariam as letras em uma curva, nem deixariam tanto espaço entre elas. Era algo proibido. Eu tentei fazer o oposto porque o desafio de explorar materiais me parecia interessante. (Farias, 2001: 26).'
}

Weingart demonstrou fidelidade à sua premissa: a de experimentar algo original e explorar as possibilidades da tecnologia disponível. Tanto que em 1984 foi um dos designers gráficos convi-dados pela Apple Computers a testar as possibilidades do desktop publishing nos primeiros com-putadores Macintosh, e passou a ser uma das principais influências no design tipográfico utilizando tal ferramenta. Seu nome está totalmente associado ao momento inicial, bem como à 


\title{
Infodesıgn
}

atitude 'desconstrucionista' perante a tipografia, embora o termo não fosse ainda corrente e muito menos adotado pelo próprio Wolfgang.

No intuito de descrever o aspecto formal de tais produtos oriundos da atitude

'desconstrucionis-ta', argumentam Lupton e Miller:

\begin{abstract}
' Desde o surgimento do termo 'desconstrução' no jornalismo especializado em design em meados dos anos (19)80, essa palavra sugestiva tem sido utilizada para designar, seja na arquitetura, no design gráfico, no design de produtos e na moda, a prática cujas formas sejam 'retalhadas', apresentem sobreposições ou aspecto fragmentado, freqüentemente imbuídas de ambíguas evocações futurísticas. (Lupton e Miller, 2000: 9).'
\end{abstract}

No entanto, como vocábulo, 'desconstrucionismo' passou a ser adotado oficialmente pela mídia após a inauguração da exposição de 1988 Deconstructivist Architecture, no MOMA, em Nova York. Na visão de Mark Wigley, um dos curadores da exposição, a 'desconstrução' na arquitetura questiona o modernismo através do reexame de sua linguagem, materiais e processos (Lupton \& Miller, 2000). Ao nomear assim a exposição, Wigley e Johnson, os dois curadores, ajudaram a estigmatizar os produtos de um determinado período que apresentassem distorção da geometria e desalinhamentos, ou que rompessem com os preceitos modernistas de alguma outra forma. Esse conjunto de características estilísticas rapidamente migrou da arquitetura para o design gráfico. O termo passou então a ser um cliché para designar as diversas manifestações da quebra do para-digma moderno. Outro termo muito em voga foi new wave, cunhado para designar o movimento oriundo de designers da Califórnia, Estados Unidos (Farias, 2001).

No início dos anos de (19)80, alunos de design gráfico de várias instituições de ensino nos EUA entraram em contato com a teoria literária através de disciplinas como fotografia, performance e instalações artísticas. A Cranbrook Academy of Art, em Michigan, foi uma das escolas que mais contribuiu para estabelecer uma relação entre teoria crítica da literatura e a prática do design gráfico, conforme descreve Priscila Farias:

\footnotetext{
' A aplicação dos termos 'desconstrução' e 'pós-estruturalismo' a um certo tipo de experimentalismo tipográfico remonta à década de 80 , sendo que a mais célebre tentativa de se fazer uma intersecção entre teoria pós-estruturalista e prática de design tipográfico ocorreu ainda no final da década de 70, quando alguns alunos de design da Cranbrook Academy of Art, sob a coordenação da designer e diretora da escola Katherine McCoy, produziram um número especial da revista Visible Language que tinha como tema as novas tendências da crítica literária francesa.'
}

\begin{abstract}
' A partir deste e de outros trabalhos de designers ligados a esta academia - bem como à Cal Arts -, 'design desconstrucionista' passou a ser um sinônimo de layout complexo, empregando elementos posicionados em diversas camadas sobrepostas e formas fragmentadas, em arranjos tipográficos que de algum modo desafiam os padrões racionalistas da leitura, muitas vezes empregando fontes criadas segundo os mesmos princípios. (Farias, 2001: 30).'
\end{abstract}

O número especial da revista Visible Language, ao qual refere-se Farias, foi publicado no verão de 1978 e pode ser considerado o marco do princípio de uma abordagem crítica, ou de uma certa atitude contestadora no design gráfico. De acordo com Lupton e Miller (Lupton e Miller, 2000), o coordenador do programa de Arquitetura da Cranbrook Academy, Daniel Libeskind, organizou um seminário sobre teoria literária que deu aos alunos de design gráfico o respaldo necessário para desenvolverem a estratégia visual apresentada na revista. Entre os autores pósestruturalistas, os que tiveram mais influência sobre os estudantes de arte e design naquela época estão: Roland Barthes, Michel Foucault, e Jean Baudrillard. Para a designer e teórica Ellen Lupton 'a tipografia torna-se um modo de interpretação, e o designer, assim como o leitor, competem com o tradicional autor pelo controle do texto' (Lupton, 2005, p:1). A idéia da "morte do autor", introduzida por Bar-thes, foi um conceito-chave para aqueles designers desenvolverem trabalhos em que o leitor ti-vesse papel ativo na construção do sentido, tentando desvendar e estabelecer relações no texto. No entanto, Katherine McCoy dá indícios de que o pós-estruturalismo nunca foi exatamente uma metodologia oficial adotada pela escola, mas sim parte de uma conjuntura eclética de idéias que circulavam naquele ambiente (Lupton e Miller, 2000).

Dessa forma fica evidente que a tipografia 'desconstrucionista' foi um produto daquela época, tendo resultado tanto de uma série de influências de áreas co-relatas, quanto de áreas afins como as artes-plásticas e a arquitetura. Para Lupton, entretanto, o termo 'desconstrução' não deve ser utilizado para definir o estilo atribuído a um determinado período. Lupton entende a 'desconstru-ção' aplicada ao design gráfico como uma atividade ou atitude crítica e contestadora (Lupton e Miller, 2000). No contexto do design gráfico a tipografia, especificamente, aparece como cerne dessa atividade crítica já que o termo foi cunhado pelo filósofo Jacques Derrida justamente para contestar os preceitos da lingüística moderna e a relação fala x escrita. 


\section{Desconstrução}

O conceito 'desconstrução' foi introduzido pelo filósofo e semioticista Jacques Derrida em seu livro De La Grammatologie, publicado na França em 1967, no qual elabora uma crítica aos textos de Ferdinand de Saussure em seu Cours de Linguistique Generale. A teoria semiótica de Saussure se dá pelo viés lingüístico. Para ele 'a relação entre a semiologia e a lingüística seria, portanto, dupla: primeiro, as leis da semiologia geral são aplicáveis à ciência dos signos lingüísticos; segun-do, as leis da lingüística são um guia heurístico na elaboração da ciência dos signos em geral' (Nöth, 1996: 19). E portanto, em conseqüência, a 'desconstrução' de Derrida se aplica sobretudo a sistemas lingüísticos ou relacionados com a produção de textos.

Em sua crítica, Jacques Derrida argumenta que a cultura ocidental, desde Platão, tende a segmentar o mundo em conceitos antagônicos tais como realidade $x$ representação, interior $x$ exterior, original $x$ cópia, e mente $x$ corpo. Para ele, sendo assim, um conceito é valorizado em detrimento do outro, ou ainda, um é visto como positivo e o outro como negativo. Nas palavras de Lupton \& Miller:

' o estruturalismo surgiu dos ensinamentos de Ferdinand de Saussure no início do século XX. A teoria lingüística de Saussure influenciou muitas outras linhas de pensamento, inclusive a antropologia de Claude Levi-Strauss, a filosofia de Jacques Derrida, e a mitologia social de Roland Barthes. Esses escritores observaram os produtos da cultura humana - dos rituais de casamento às bolhas de sabão - em termos de sistemas de oposição, padrões de diferenças que geram significado. (Lupton e Miller, 2000: 53).'

Do ponto de vista da semiótica de viés lingüístico, uma das duplas de conceitos opostos que veio a ser crucial para a teoria da 'desconstrução' é a fala x escrita. A tradição filosófica ocidental, especialmente na figura de Saussure, denegrira a escrita colocando-a como uma cópia inferior da palavra falada: a palavra escrita não teria conexão com o ser interior - enquanto a fala teria - e neste caso a língua é abandonada e desvinculada do sujeito. A oposição fala x escrita pode ser mapeada em uma série de pares com conotações ideológicas que pertencem à cultura ocidental moderna:

- Fala x escrita;

- Natural $x$ artificial;

- Espontânea x planejada;

- Original x cópia;

- Interior da mente $x$ exterior á mente;

- Não requer equipamento x requer equipamento;

- Intuitiva $x$ apreendida;

- Sujeito presente $x$ sujeito ausente.

Já a 'desconstrução' propõe que a escrita seja uma forma ativa de representação: não se re-sume a uma mera cópia da palavra falada. Na verdade, 'a escrita invade o pensamento e a fala, transformando os reinos sagrados da memória, conhecimento e espírito.' (Lupton e Miller, 2000: 4).

\section{Estruturalismo}

A crítica de Derrida à oposição fala $x$ escrita desenvolveu-se a partir da leitura do Cours de Lin-guistique Generale, de Ferdinand de Saussure, um dos alicerces da lingüística moderna, da semi-ótica e da antropologia. Para Saussure, o significado dos signos lingüísticos não reside nos pró-prios signos: não existe elo natural entre o significante e o significado. Em suas palavras: 'o laço que une o significante ao significado é arbitrário ou, então, visto que entendemos por signo o total resultante da associação de um significante com um significado, podemos dizer mais simplesmen-te: o signo lingüístico é arbitrário.' (Saussure apud Nöth, 1996: 26).

Devido ao caráter arbitrário do signo lingüístico, seu significado é alcançado apenas por causa de sua relação com outros signos de um sistema. Esse é o princípio-base do estruturalismo: uma compreensão da língua como um sistema gerador de significados a partir dos padrões produzidos, ao invés de focar no conteúdo de um código ou costume isoladamente. Saussure entende que o signo por si só é vazio de significado: não tem "vida" fora do sistema ou "estrutura" da língua que o cerca. Ele sustenta ainda que a língua não é como uma janela transparente que permita vislum-brar conceitos pré-existentes, mas que a língua é um sujeito ativo na elaboração de idéias. Ou seja, ao invés de considerar a língua como um código que passivamente representa 'os 


\section{Infodesign}

pensa-mentos', Saussure coloca que os pensamentos é que são delineados através da língua, sem a qual seriam apenas esboçados, amorfos. Nas palavras de Winfried Nöth:

' De acordo com a visão estruturalista da semântica de Saussure, o significado é o valor de um conceito dentro do sistema semiológico como um todo. Estes valores semânticos formam uma rede de relações estruturais, nas quais não os conceitos semânticos em si, mas somente as diferenças ou oposições entre eles são relevantes semioticamente. (Nöth, 1996: 35).'

' (E ainda) as relações estruturais mais fundamentais num sistema semiológico são as da diferença e da oposição (cf. Nöth, 1994). Segundo a teoria saussureana do valor, os elementos de um sistema semiótico só existem pelas suas diferenças com outros signos (...) (Nöth, 1996: 45).'

Saussure ainda desenvolve, em sua teoria, uma crescente aversão à palavra escrita $\mathrm{e}$ defende a precariedade desta para representar a fala. Para ele, há várias divergências entre a fala e a es-crita: por exemplo, palavras com sonoridade semelhante são, no entanto, soletradas de modo di-verso, e ocorrência de letras cuja combinação gera sons inesperados. Portanto, sua teoria é de-nominada logocentrista, já que ele defende a supremacia da palavra falada sobre a escrita.

\section{Pós-estruturalismo}

Na década de (19)60 Jacques Derrida vem a questionar o pensamento estruturalista, embora para muitos ele mesmo ainda seja considerado um estruturalista já que suas proposições têm como ponto de partida as idéias de Saussure. Para tantos outros, porém, ele é designado como neo-estruturalista, superestruturalista, ou ainda pós-estruturalista. O termo 'desconstrução', por ele cu-nhado, insere-se então nesta área da crítica literária muito mais ampla, designada enfim como 'pós-estruturalismo', e cujos autores compreendem os meios de representação cultural - a literatu-ra, a fotografia, o design de um modo geral etc - como poderosas tecnologias que constroem e re-constroem o nosso mundo. Portanto, os pós-estruturalistas se opõem, em suas obras, à neutrali-dade dos signos isolados, sendo que para Derrida em particular, o foco será o signo lingüístico já que sua crítica se forma a partir da teoria logocentrista de Saussure. Em outras palavras, os pós-estruturalistas questionam a supremacia do sistema, ou estrutura, como gerador do significado.

Para Jacques Derrida os textos escritos, bem como a tipografia, têm características próprias de representação que não estão necessariamente vinculadas à fala. Um exemplo disso seria a pró-pria determinação ou formatação do texto, através dos espacejamentos - entreletras e entrelinhas, pontuação, escolha da fonte, ou mesmo a variação de estilo numa fonte como o romano, o itálico, e a variação de caixa - alta, baixa ou versalete. Dessa forma, a comunicação escrita não se dá apenas através do sentido das palavras, mas faz uso de todo um repertório próprio que não se traduz em palavras. Tal proposição liberou os designers para manipularem mais livremente os tex-tos em seus projetos visuais, de forma a trabalharem a tipografia como uma forma independente de representação. Derrida denominou 'gramatologia' o estudo da escrita como um modo distinto de representação, o qual deu nome à sua obra mais conhecida: De La Grammatologie.

Fica, então, patente que enquanto Saussure acusava a escrita/tipografia de não oferecer uma transparência ao significado final do texto, Derrida pretendeu realçar o potencial retórico da escrita por meio da tipografia e assim valorizar o significante e a 'desconstrução' do significado. Daí que a ênfase do pós-estruturalismo na liberdade, ou possibilidades de interpretação, liberou os designers gráficos para, assim como os leitores, atuarem de forma espontânea na criação de significados.

\section{A semiótica de Saussure $x$ o modelo de Peirce}

Enquanto Ferdinand de Saussure empenhou-se em desenvolver uma teoria semiótica de referên-cia lingüística, que deu origem ao estruturalismo, Jacques Derrida elaborou um contraponto ao estruturalismo que veio a ser denominado 'gramatologia'. Muito embora Saussure acreditasse que a escrita seja meramente uma forma de representação da fala - ou seja: um sis-tema de signos cuja função é a de representar outros signos - e Derrida propusesse que a escrita seja um sistema de signos com 'vida própria', independente da fala, a segunda teoria é derivada da primeira e ambas referem-se a signos lingüísticos.

Entretanto, a tipografia, enquanto sistema de signos, não deveria ser classificada meramente como sistema de representação lingüística, já que há outras esferas de representa-ção ocorrendo concomitantemente à esfera lingüística. Afinal, o universo da tipografia a-brange não só uma infinidade de desenhos de fontes distintas como também possibilidades inesgotáveis de 
formatação para textos que vão determinar valores sintáticos à escrita, além daqueles semânticos. Donde se pode concluir que a tipografia não oferece apenas uma in-terface ao alfabeto como toda uma significação expressiva de qualidades estéticas e cultu-rais.

Os conceitos teóricos de sintaxe e semântica são elementares à teoria da comunicação e podem ser descritos da seguinte maneira: o fato de um signo só funcionar como tal quando se refere a algo ou quando deveria significar alguma coisa é chamado de função semântica. Por exemplo, se tomada a palavra "ombro", cujo significado ulterior é um membro do corpo humano, é possível decompô-la em diferentes signos lingüísticos básicos: as letras o, $\mathrm{m}, \mathrm{b}, \mathrm{r}$ e novamente 0 . Porém, a relação das letras entre si e com o suporte (papel, tela, ou outro qualquer) será denominada de função sintática do signo. O tipógrafo e inovador Wolfgang Weingart assim coloca no livro "Como se pode fazer tipografia Suíça?": 'só podemos fazer tipografia hoje se compreendermos sua dimensão sintática. Dito de forma mais simples, a dimensão sintática da tipografia é, para mim, um território novo.' (Weingart, 2004: 33).

Os limites colocados pela linha francesa clássica - não se atribui à tipografia sua característica inerente para gerar significados - criticada por Derrida por ser logocêntrica, não existem na teoria semiótica de Charles Sanders Peirce. A teoria peirciana não tem sua origem na lingüística e sim na lógica, e portanto, não há a supremacia dos signos lingüísticos sobre os outros signos na visão do filósofo. Faz-se, pois, mister propor uma decupagem dos signos tipográficos, ou da tipografia, a partir de princípios e preceitos proposto por Peirce.

\section{A tríade de Peirce para análise da tipografia}

Para o semioticista americano Charles Sanders Peirce, a semiótica possui aplicações que se es-tendem para muito além da lingüística, sendo que a língua seria, para ele, um dentre os vários outros sistemas de signos. Tal compreensão da palavra 'signo' possui dois significados: um deles é mais amplo e designa a própria relação triádica estabelecida pelas partes componentes do sig-no; o outro significado é mais restrito e serve para nomear especificamente um dos componentes nesta relação triádica, também denominado representamen.

Os três elementos que formam o modelo peirciano são: o representamen ou signo (em seu sentido restrito); o objeto representado, que se manifesta através do representamen; e o interpre-tante, que é o efeito que o representamen provoca na mente do receptor ou intérprete. 0 interpre-tante pode também ser compreendido como um segundo signo gerado na mente do receptor a partir do signo original quando associado a seu objeto.

Figura 1: Concepção do signo triádico por C. S. Peirce. (Mollerup, 1999: 78).

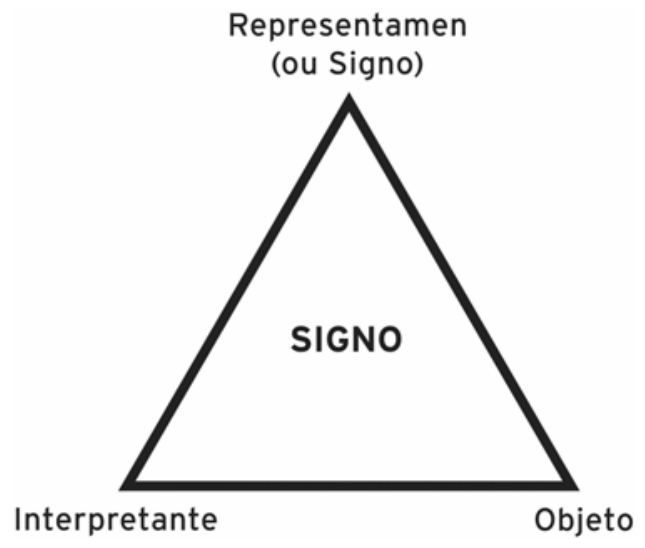

Ao considerar o objeto de interesse deste artigo, a tipografia, depara-se com um tipo de signo que é lingüístico mas que igualmente possui qualidades pictóricas e visuais. Por exemplo, as ca-racterísticas visuais de uma determinada fonte e sua disposição sobre a página (layout) podem sugerir determinado conteúdo por estabelecer similaridade ou algum tipo de paralelismo visual com o objeto que pretendem representar.

Peirce classifica os signos em basicamente nove tipos, conforme a tabela a seguir: 
Tabela 1: Classificação básica dos signos

\begin{tabular}{|c|c|c|c|}
\hline Categoria & $\begin{array}{l}\text { O Signo em relação a si } \\
\text { mesmo }\end{array}$ & $\begin{array}{l}\text { O Signo em relação ao } \\
\text { objeto }\end{array}$ & $\begin{array}{l}\text { O Signo em relação ao } \\
\text { interpretante }\end{array}$ \\
\hline Primeiridade & Quali-signo & Ícone & Rema \\
\hline Secundidade & Sin-signo & Índice & Dicente \\
\hline \multirow[t]{2}{*}{ Terceiridade } & Legi-signo & Símbolo & Argumento \\
\hline & $\begin{array}{l}\text { Nesta coluna: a relação } \\
\text { é de representação }\end{array}$ & $\begin{array}{l}\text { Nesta coluna: a relação } \\
\text { é de objetivação }\end{array}$ & $\begin{array}{l}\text { Nesta coluna: a relação } \\
\text { é de interpretação }\end{array}$ \\
\hline
\end{tabular}

Tendo em vista a classificação acima, a tipografia poderá ser interpretada de diversas formas. Por exemplo, tomando-a por signo lingüístico, com relação ao objeto representado, a tipografia é um signo simbólico: um símbolo tem uma relação com seu objeto estabelecida por convenção. Entretanto, ao se considerar seus atributos visuais e pictóricos - cuja categoria é a primeiridade - também com relação ao objeto representado, a tipografia poderá tornar-se signo icônico: 'quando a relação se estabelece pela semelhança ou analogia entre as qualidades da manifestação per-ceptível e aquilo que está sendo representado e seu significado'. (Nojima, 2007, no prelo).

Durante o processo de significação, um fato ou coisa qualquer poderá desencadear diversas interpretações simultâneas ou seqüenciais na mente do receptor ou intérprete. Tal ocorrência pode ser entendida, de acordo com Per Mollerup como uma interpretação com um 'interpretante com-plexo', que é constituído de várias camadas (Mollerup, 1999). Na ilustração esquemática a seguir, foram representadas as seqüências iniciais da análise do signo tipográfico sob seu aspecto pura-mente lingüístico. O representamem inicial (ou signo original) são os layouts tipográficos, ou pági-nas, que por sua vez representam sons, de forma convencional. O interpretante é a capacidade de ler tais signos transformando-os em sons. Na seqüência, o representamem é o conjunto de sons idealizados, cujos objetos são conceitos associados a estes sons. O interpretante final do proces-so descrito acima é a construção mental de imagens associadas a tais sons.

Figura 02: O modelo triádico quando utilizado para decupar a tipografia sob seu aspecto lingüístico poderá gerar um desencadeamento de signos seqüenciais, ou um 'interpretante complexo', conforme propõe Mollerup.

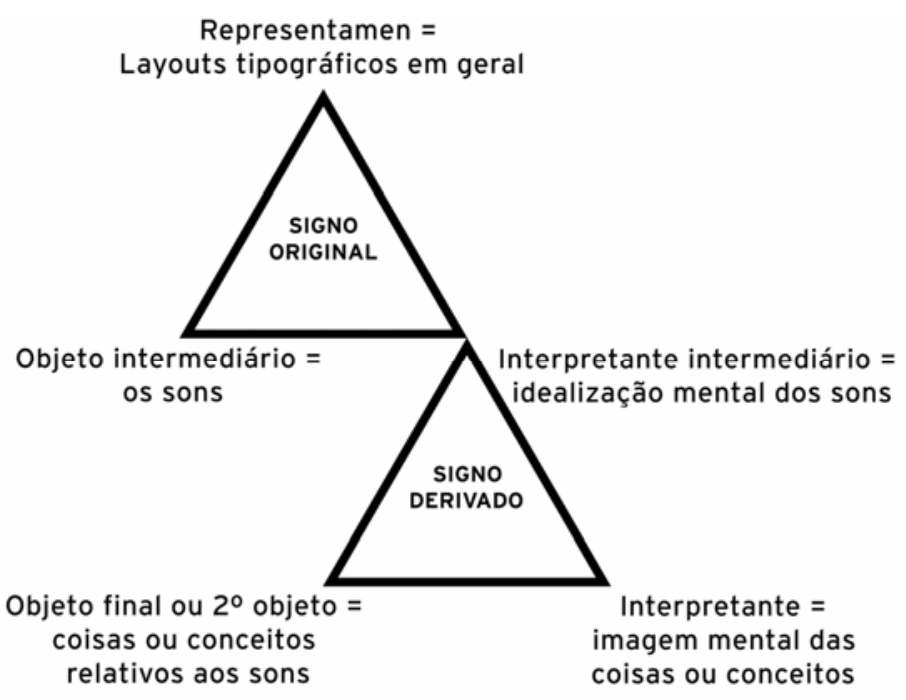

O modelo que Mollerup propõe, de interpretações seqüenciais, pode ser aplicado à decupagem do signo tipográfico, já que este oferece a significação lingüística que corresponde à significação denotativa deste signo, bem como significações estéticas e culturais que seriam as significações conotativas. Por significação denotativa compreende-se aquele vínculo direto de significação que um nome ou signo verbal estabelece com seu objeto, sem sentidos derivativos ou figurados. Por significação conotativa entende-se que um signo possua uma série de atributos implícitos em seu significado, para além do vínculo direto e imediato que mantém com seu objeto (o vínculo direto, neste caso, seria o sentido lingüístico do signo tipográfico). No exemplo a seguir foi proposta uma análise do signo tipográfico de acordo com o modelo de significação seqüencial de Per Mollerup, e parte-se da premissa de que o signo visual tenha um impacto anterior ao signo 
lingüístico sobre o intérprete, afinal a seqüência natural seria: um indivíduo primeiramente 'vê' para em seguida 'ler'.

Figura 03: Conforme representado ao lado, o signo tipográfico é primeiramente enxergado por suas qualidades formais para depois, num segundo momento imediatamente consecutivo, ser interpretado como signo lingüístico.

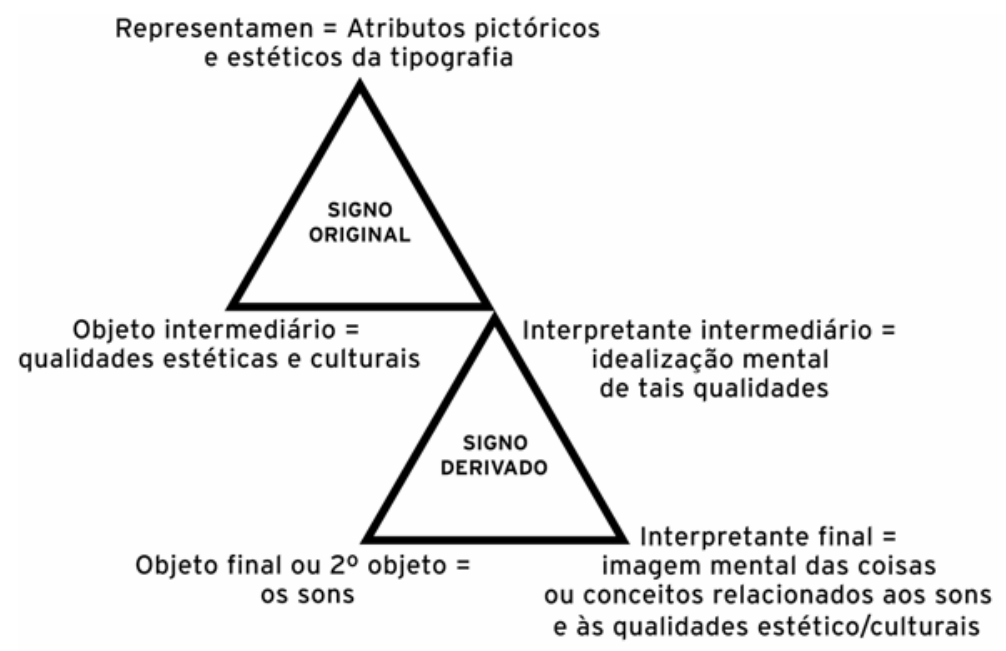

\section{Códigos e tipografia}

Em semiótica, um código corresponde a um sistema de signos que assume relações que por sua vez geram significados. Lupton e Miller inicialmente questionam para depois afirmarem:

' Que tipo de sistema semiótico é a tipografia? O alfabeto foi designado para representar a fala. A escrita é portanto uma linguagem que descreve outra linguagem, um conjunto de signos para representar outros signos. O design de fontes é levado ainda mais adiante: é um meio cuja significação não é a palavra mas sim o alfabeto. (Lupton e Miller, 2000: 55). '

O alfabeto, por sua vez, pode ser classificado, de acordo com Pierre Guiraud (Mollerup apud Guiraud, 1999: 80-81), como um código lógico da categoria dos paralingüísticos, sendo que um código lógico é do tipo objetivo com uma forte, e geralmente explícita, convenção. Ainda segundo Guiraud, do outro lado, em oposição aos códigos lógicos, estariam os códigos expressivos e sub-jetivos, tais como a moda, os rituais e as artes. No entanto, os códigos, geralmente, permeiam uma intersecção entre puramente lógicos e puramente expressivos. A tipografia, por exemplo, é a manipulação de um código lógico - o alfabeto - e o designer determina seu arranjo visual e espa-cial. Na tipografia pós-moderna especificamente, a manipulação do código (letras) é livre das con-venções modernistas e estruturalistas. Sendo assim, o código é portanto não somente lógico como também expressivo e subjetivo pois estará sujeito aos sentimentos pessoais e à carga emotiva do designer/tipógrafo e à mercê de suas escolhas e interpretações do conteúdo do texto em questão.

\section{Conclusão}

É possível constatar que a tipografia 'desconstrucionista' surgiu sobretudo da necessidade de res-gatar a liberdade de expressão individual, sem que os designers se importassem com restrições de cunho funcional ou funcionalista - muito em voga até os anos (19)70 por influência do Estilo Internacional, ou Suíço. Ou ainda, os designers passaram a valorizar e explorar as possibilidades sintáticas da tipografia através de uma nova ferramenta, conforme propôs Wolfgang Weingart. Os designers da Cranbrook Academy foram os precursores deste tipo de abordagem no design gráfi-co, ao tentarem dar visualidade a certos conceitos filosóficos do pós-estruturalismo no número especial da revista Visible Language, publicado no verão de 1978, que estabeleceu um marco no design pós-moderno. Não seria correto afirmar, no entanto, que todos os designers desta cena foram influenciados diretamente pelos pensadores pós-estruturalistas, mas, sob o olhar dos críti-cos de design, há uma estreita afinidade entre essa corrente filosófica e o resultado estético da-queles trabalhos.

O semioticista Jacques Derrida foi personalidade fundamental para o desenvolvimento da cor-rente de pensamento pós-estruturalista chamada de 'desconstrução'. Sua crítica ao 


\section{Infodesıgn}

estruturalismo e ao logocentrismo de Ferdinand de Saussure em muito contribuiu para alçar a escrita, e conse-quentemente a tipografia, a uma categoria a parte, independente da fala. Em sua obra ele valoriza e enfatiza o repertório próprio da tipografia, que não encontra correspondência na fala, e sobretu-do defende que a significação da tipografia não está vinculada à estrutura da língua. Daí propõe a 'desconstrução' do signo 'estruturado'.

A semiótica de Derrida possibilitou a quebra de paradigma, ou pelo menos elucidou o princípio intelectual por trás da mudança ocorrida no design gráfico em meados dos anos (19)80. No entan-to, sua teoria não fornece um modelo lógico que possibilite a decupagem do signo tipográfico e a compreensão das esferas de significação ali envolvidas. Tal modelo foi encontrado no conceito de signo proposto na teoria semiótica de Charles Sanders Peirce, o qual propôs uma teoria geral dos signos pelo viés da lógica, e não da lingüística, afinal o signo tipográfico é lingüístico assim como também é pictográfico e visual. Sendo assim, aplicando o modelo seqüencial do signo triádico peirciano - desenvolvido por Per Mollerup - foi possível investigar, no intuito de melhor compre-ender, os níveis de significação dos signos tipográficos.

$\mathrm{E}$, finalmente, após certas averiguações deste artigo com relação às origens do termo 'des-construção', o título inicialmente proposto para da pesquisa de Doutorado em andamento sobre a tipografia 'desconstrucionista' no Brasil, "Tipografia pós-moderna no Brasil: o produto da estética 'desconstrucionista' e suas representações", passa a ser questionável. Afinal, a 'desconstrução' não é um conceito que se refere à estética, e sim um conceito que questiona uma linha de pensa-mento anterior: o estruturalismo. No entanto, quando relacionado ao design gráfico, pelos teóricos e críticos de design, 'desconstrução' serve para identificar os produtos de uma determinada época cujo aspecto estético reflete conceitos e pensamentos da linha pósestruturalista / desconstrucio-nista, muito embora essa não tenha sido necessariamente a intenção do designer / autor.

\section{Agradecimento}

Aproveito para agradecer ás minhas orientadoras no Doutorado, que têm compartilhado comigo seus conhecimentos de forma generosa: Vera Lúcia Nojima e Priscila Farias. Muito obrigada pelo apoio presente e futuro.

\section{Referências}

Farias, P. (2001). Tipografia digital. O impacto das novas tecnologias. Rio de Janeiro: Editora $2 A B, p p .92$.

Lupton, E. (2005). The birth of the user. AIGA Journal of Design: www.aiga.org/content.cfm/thebirth-of-the-user.

Lupton, E. \& Miller, J. A. (2000). Deconstruction and graphic design: history meets theory. London: Phaidon Press Limited, pp. 7, 8, 9, 10

Mollerup, P. (1999). Marks of excellence - The history and taxonomy of trademarks. London: Phai-don, pp. 78, 81.

Nojima, V. L. (2007). Verbetes: Semiótica e Significado. In: Coelho, L. A. (org). Termos Chave no Design. Rio de Janeiro: Novas Idéias - PUC-Rio (no prelo).

Nöth, W. (1996). A semiótica no século XX. São Paulo: Annablume.

Weingart, W. (2004). Como se pode fazer tipografia suíça? São Paulo: Edições Rosari.

\section{Sobre as autoras}

Mirella De Menezes Migliari, Doutoranda em Design pela PUC-Rio, desenvolvendo pesquisa relacionada à tipografia pós-moderna no Brasil. Mestre em Design Gráfico pela Central Saint Martins, Londres (1998). Desenhista Industrial graduada pela ESDI (1995). É professora na ESPM e na Universidade Estácio de Sá. Atua ainda como consultora de Design gráfico e Direção de Arte.

mirella.migliari@gmail.com 
Vera Lúcia M. dos Santos Nojima, Doutorado em Arquitetura e Urbanismo pela USP (1991). É Professora do Programa de Pós Gra-duação em Design da PUC-Rio. Vinculada à Linha de Pesquisa Design, Comunicação, Cultura e Artes, coordena o Laboratório de Comunicação no Design e orienta alunos de mestrado e douto-rado.

nojima@rdc.puc-rio.br 